\title{
A Canine Model of a Completely Ischemic Brain Regulated with the Perfusion Method
}

Takamasa Kayama, M.D., Kazuo Mizoi, M.D., and Jiro Suzuki, M.D.

Reprinted from Surgical Neurology, Volume 16, Number 3, September, 1981. Published by Little, Brown and Company, Boston, Massachusetts. Copyright (C) 1981 by Little, Brown and Company (Inc.). All rights reserved. No part of this reprint may be reproduced in any form or by any electronic or mechanical means, including information storage and retrieval systems, without the publisher's written permission. 


\section{A Canine Model of a Completely Ischemic Brain Regulated with the Perfusion Method}

Takamasa Kayama, M.D., Kazuo Mizoi, M.D., and Jiro Suzuki, M.D.

Using dogs (previously considered unsuitable for research on infarction of the brain because of their extensive collateral cerebral circulation), we have produced ischemic foci in the thalamus, the cerebral mantle, and the entire cerebral hemisphere by occluding various combinations of cerebral vessels at the base of the brain. A unilateral temporal approach was utilized in identifying and occluding all of the bilateral trunk arteries. By a variation of vascular occlusion (inserting a cannula retrogradely into the middle cerebral artery [MCA] on the operated side and pumping autologous blood from the femoral artery to the opposite MCA, while producing a condition of complete ischemia in the contralateral hemisphere, which is then perfused with the autologous blood), we have produced an experimental model in which blood flow to the contralateral hemisphere can be freely controlled. By controlling the volume of perfused blood, various degrees of hy. peremia, incomplete ischemia, and complete ischemia can be produced. At the same time, physiological conditions can be maintained and recirculation following ischemia can be easily performed. Also, known quantities of drugs can be delivered to the brain, and sequential changes can be measured over long periods.

Kayama T, Mizoi K, Suzuki J: A canine model of a completely ischemic brain regulated with the perfusion method. Surg Neurol 16:167-172, 1981

Using various experimental models, many researchers have investigated the pathophysiology of brain ischemia, but previous occlusion models $[1-3,6,7,10-12,14,15,17$, $18]$ and embolization methods $[13,16,19]$ have had a low success rate in producing ischemic foci, and the site and size of the foci have not been consistent. Furthermore, the degree of ischemia has not been subject to control, so the ability to produce a complete focus has remained unattainable.

From the Division of Neurosurgery, Institure of Brain Diseases, Tohoku University School of Medicine, Nagamachi, Sendai, Japan.

Address reprint requests to Dr. Takamasa Kayama, Division of Neurosurgery, Institute of Brain Diseases, Tohoku University School of Medicine, 5-13-1 Nagamachi, Sendai, Japan, 982.

Key words: brain ischemia; perfusion method; cannulation; middle cerebral artery; occlusion; dog.
To examine the pathology of the brain following recirculation of blood-an important problem with regard to clinical treatment-it is first necessary to produce a focus of complete ischemia to which blood or drugs can be delivered in a controlled manner. Only then will reliable data be obtainable.

By means of a unilateral temporal approach, we have found it possible to dissect all of the arteries entering and leaving the circle of Willis in the dog. We have also been able to occlude various combinations of trunk vessels and thereby freely control the degree of ischemia produced at various cerebral sites [21-23]. We have developed a technique by which it is possible to control the degree of cerebral blood flow to the left cerebral hemisphere.

\section{Experimental Method}

Adult mongrel dogs weighing about $10 \mathrm{~kg}$ each were used. Anesthesia was induced by intravenous administration of 25 milligram per kilogram of body weight of thiopental sodium (Ravonal), after which immobilization was maintained by intravenous administration of $0.2 \mathrm{mg} / \mathrm{kg}$ of pancuronium bromide (Myoblock). Regulated respiration was instituted, and no further anesthesia was administered. Throughout the operation body temperature was maintained at $37^{\circ} \mathrm{C}$, blood pressure at $90-120 \mathrm{~mm} \mathrm{Hg}, \mathrm{PaO}_{2}$ at $100 \mathrm{~mm} \mathrm{Hg}, \mathrm{PaCO}_{2}$ at $37 \mathrm{~mm} \mathrm{Hg}$, and arterial pH at 7.4 . Electrical activity of the brain (EEG) was recorded from two stainless-steel electrodes placed on the dura mater above the left parietal lobe. For measurements of regional cerebral blood flow (rCBF), platinum-wire electrodes were implanted bilaterally in the cortex fed by the anterior cerebral artery (ACA) and $\mathrm{rCBF}$ was measured by the hydrogen-clearance method (Fig. 1).

After removal of the right zygomatic arch, a right temporal craniotomy was performed, with sufficient removal of bone in a caudal direction. After opening a $4 \times 3 \mathrm{~cm}$ window in the bone, the dura mater was cut over the right temporal lobe. By use of a surgical microscope, the trunk .arteries of the brain were approached, and the left and right internal carotid arteries (ICA), opthalmic arteries, ethmoidal arteries, right posterior cerebral artery (PCA), and right anterior cerebellar artery and basilar artery were dissected free without damaging the brain itself. The left 


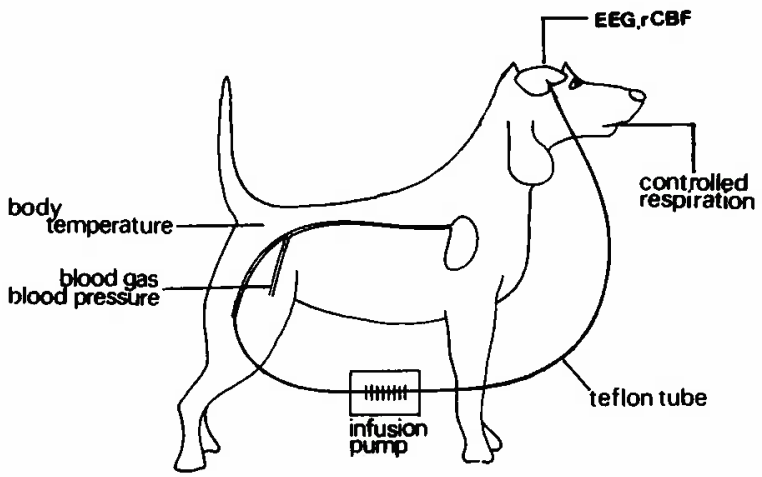

Fig. 1. Plan of the model: perfusion of blood to the right MCA from the femoral artery.

cerebral hemisphere was not exposed at this time. A polyethylene tube (diameter, $3 \mathrm{~mm}$ ) from the femoral artery was attached to a peristaltic infusion pump (Model 1210). * The tip of the tube was narrowed to a diameter of $600 \mu$ to allow for retrograde insertion into the right MCA. At the time of perfusion of the brain with the autologous blood, 150 units $/ \mathrm{kg}$ of heparin were administered intravenously, with 150 units/kg every hour thereafter.

A Scoville aneurysmal clip was then placed immediately below the bifurcation of the right MCA and ICA. The MCA was severed $1 \mathrm{~cm}$ peripherally. The peripheral portion was then cauterized, and the polyethylene tube was inserted retrogradely for $1 \mathrm{~cm}$ into the MCA as far as its origin. The tube and artery were firmly bound with adhesive agents. After complete adhesion, the clip on the right MCA was removed. The right ophthalmic and the right ethmoidal and left ethmoidal arteries were then cauterized, in that order. After the right optic nerve was severed, the left ophthalmic artery was cauterized. Finally, the right PCA and the right anterior cerebellar artery were cauterized, and 150 units $/ \mathrm{kg}$ of heparin were administered. The infusion pump cannulated into the right MCA was then started, and the brain was gradually perfused with autologous blood. Clipping of the basilar artery was done simultaneously with an increase to $4 \mathrm{ml} / \mathrm{min}$ of perfusion through the cannulation tube. This was followed by clipping the right ICA and increasing the blood being perfused to $8 \mathrm{ml} / \mathrm{min}$, then clipping the left ICA and increasing to $16 \mathrm{ml} / \mathrm{min}$. (In this model the ACA is not occluded because the $A_{2}$ portion cannot be seen in the dog from the exterior of the brain, and it is not easily dissected.) The left cerebral cortical EEG was monitored throughout the procedure. The blood flow to the left cerebral hemisphere was thus completely separated from the usual intracranial circulation, allowing complete control of cerebral blood flow through the cannula to the right MCA (Fig. 2). Using this model, we have made the following observations.

${ }^{*}$ Harvard Co., Millis, MA.

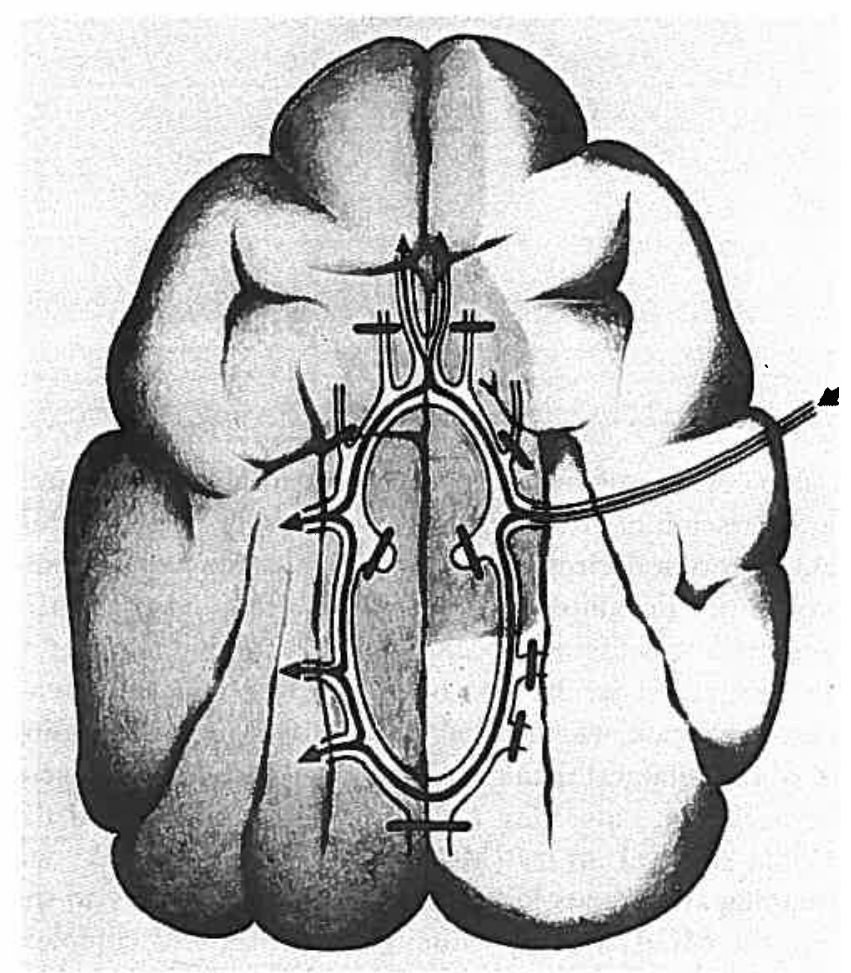

Fig. 2. The main arteries of the brain, showing the occluded points and the distribution of blood from the perfusion through the cannulated tube introduced retrogradely into the right $\mathrm{MCA}$.

CEREBral PERfusion by CARBon black SOlution. A total volume of $15 \mathrm{ml}$ of a $10 \%$ formalin and carbon black solution was delivered to the brain through the cannulated right MCA at a temperature of $37^{\circ} \mathrm{C}$ and a speed of 16 $\mathrm{ml} / \mathrm{min}$. Immediately thereafter, $15 \mathrm{ml}$ of a $10 \%$ potassium chloride solution was injected intravenously to arrest cardiac activity. The brain was then removed and the brain surface and coronal sections of the chiasmal region were examined for the presence of carbon black.

MEASUREMENT OF MEAN BLOOD PRESSURE IN THE LEFT MCA. After the dura mater on the left side was cut, the trunk of the left MCA was dissected in the posterior sylvian fissure by means of a surgical microscope. A polyethylene tube (diameter, $600 \mu$ ) was inserted retrogradely and connected to a pressure transducer. While the volume of infused blood to the right MCA was being increased, the mean blood pressure of the left MCA was measured.

MEASUREMENT Of TCBF. One window $(1 \times 1 \mathrm{~cm})$ was opened on each side over the frontal lobes fed by the anterior cerebral arteries. After the dura mater was cut, platinum-wire electrodes were inserted 1 to $2 \mathrm{~mm}$ into the cortex, and bilateral rCBF measurements were made using the $\mathrm{H}_{2}$ clearance method while the volume of infused blood was being altered. 


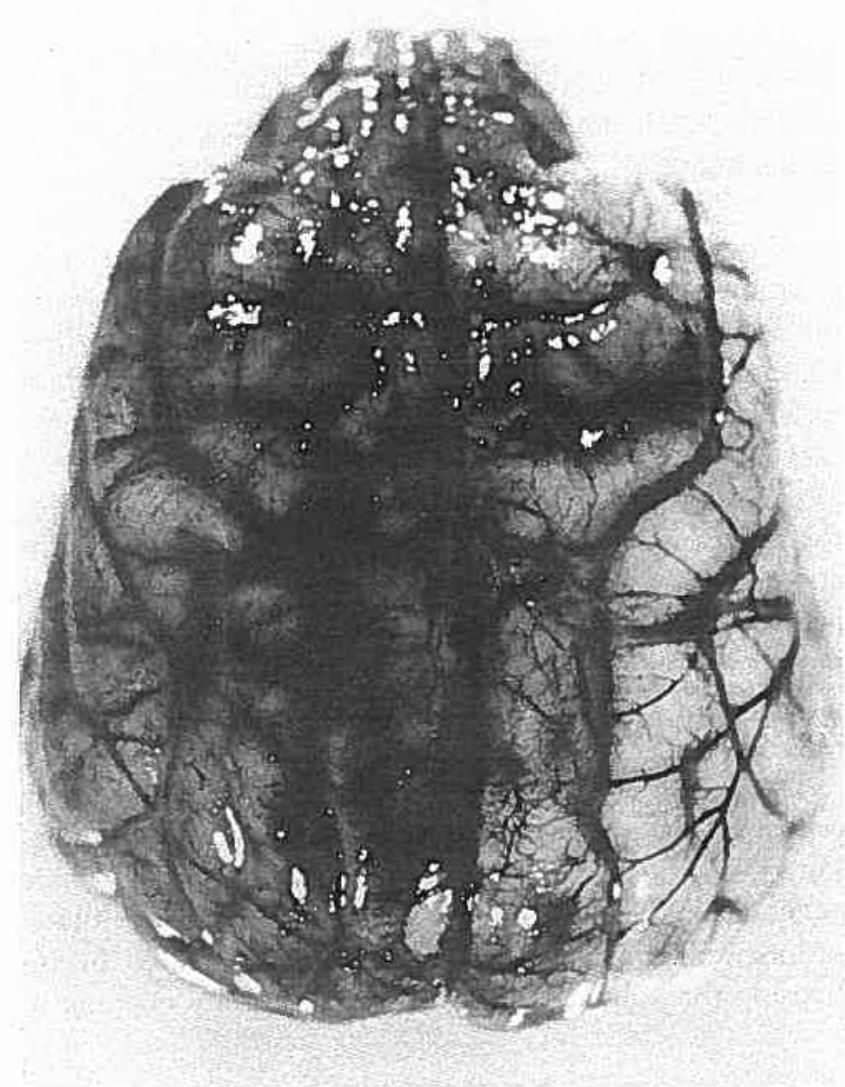

Fig. 3. Dorsal view of brain perfused with carbon black through the right MCA. Note that the left hemisphere is perfused diffusely and the right hemisphere is perfused only in the territory of the right ACA.

LEFT PARIETAL Eeg. While the volume of blood being infused into the right middle cerebral artery was being altered, the electrical activity of the left cerebral hemisphere was measured.

\section{Experimental Results}

CEREBRAL PERfuSION BY CARBON BLACK SOLUTION. Carbon black was seen over the entire dorsal surface of the left hemisphere, but only in the area fed by the anterior cerebral artery in the right hemisphere (Fig. 3). Coronal sections through the chiasmal region showed carbon black throughout the left hemisphere, including the thalamus and the hypothalamus. On the right side, however, carbon black was found only in the cerebral mantle in the areas thought to be fed by the ACA, that is, the frontal and medial parietal cortex (Fig. 4).

LEFT MCA ARTERIAL PRESSURE AND VOLUME OF INFUSED BLOOD. Left MCA blood pressure was found to be directly proportional to the volume of infused blood. Increases from 0 to $18 \mathrm{ml} / \mathrm{min}$ caused increases in blood pressure from 0 to $170 \mathrm{~mm} \mathrm{Hg}$ (Fig. 5).

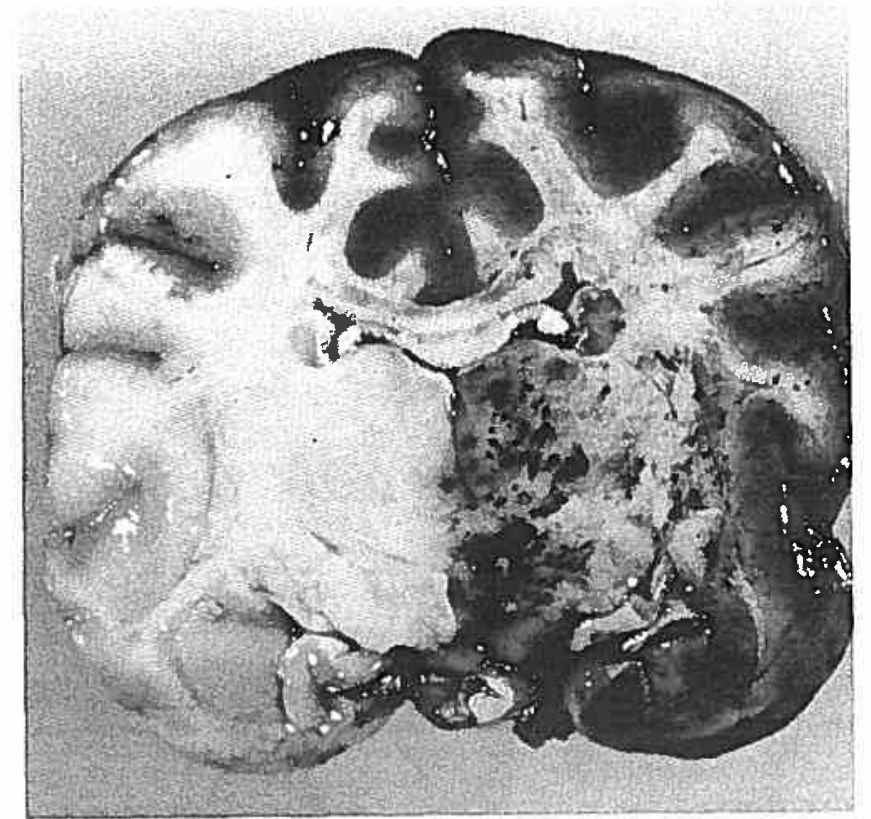

Fig. 4. Coronal view of brain perfused with carbon black through the right MCA. Note that the left hemisphere is perfused diffusely and the right hemisphere is perfused only in the territory of the right $A C A$.

VOLUME OF INFUSED BLOOD AND TCBF OF THE CORTEX FED BY THE ACA. The volume of infused blood necessary to maintain an $\mathrm{rCBF}$ of $28 \mathrm{ml} / 100 \mathrm{gm} / \mathrm{min}$ (the value obtained on the left side prior to the operation) was between 14 and 23 $\mathrm{ml} / \mathrm{min}$. Above or below such values, the $\mathrm{rCBF}$ was above or below the normal range. In contrast, a roughly linear correlation between the volume of blood infused on the right side and rCBF was seen (Fig. 6).

CHANGES IN VOLUME OF INFUSED BLOOD AND LEFT PARIETAL CORTICAL ACrIVITY. When the volume was maintained between 14 and $20 \mathrm{ml} / \mathrm{min}$, no notable differences were seen in electrical activity between preoperative and postoperative recordings. At lower volumes, there was a gradual slowing and flattening of electrical activity, with complete flattening when the pump was shut off and the volume brought to zero. At a volume of $16 \mathrm{ml} / \mathrm{min}$, normal electrical activity was maintained for the entire 5-hour observation period (Fig. 7).

\section{Discussion}

Perfusion of the brain has been done since the 1930s as part of research on brain metabolism [4]. In order to separate brain circulation from systemic circulation, blood vessels, bone, and cartilage of the neck have been severed and circulation has been established between the bilateral carotid veins and arteries. Autonomic nerves in the vicinity of the ICA have been cut, the venous system has not been preserved in a physiological state, and the perfused blood has 


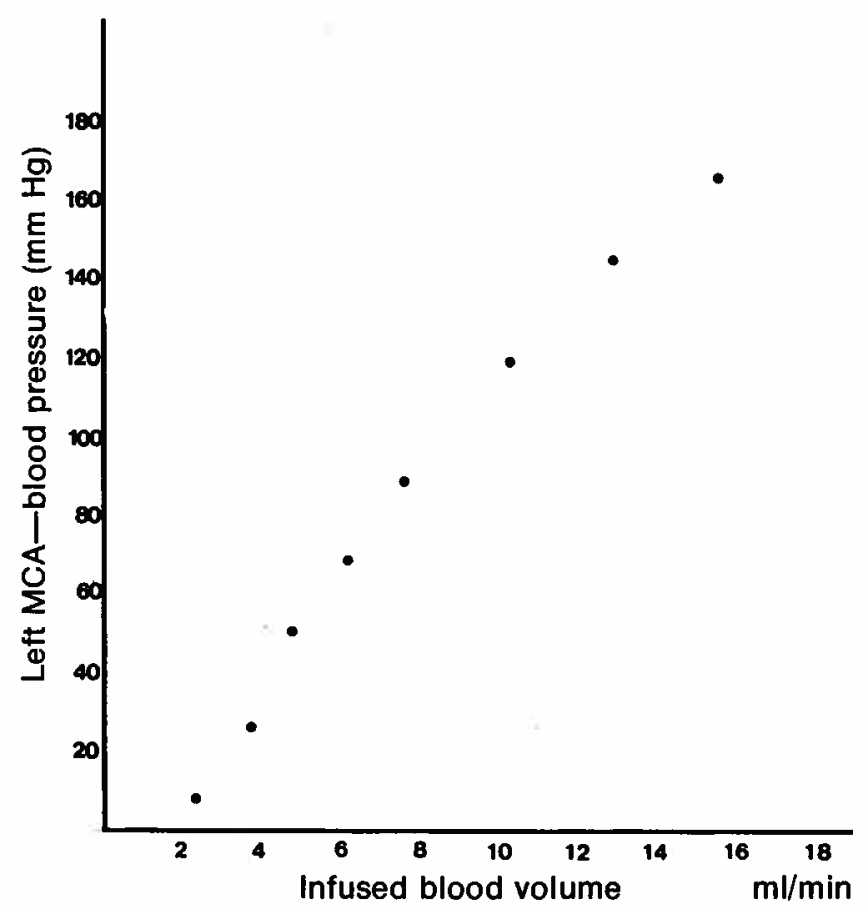

Fig. 5. Correlation between volume of infused blood and blood pressure in the left MCA. not been autologous. Consequently, it has been believed that autoregulation of the vessels of the brain is necessarily lost $[8,17,20]$, and that nonphysiological factors play an important role in producing inevitably inconsistent experimental data $[5,9]$.

Initially, we tried to prepare a dog model in which a tube was inserted anterogradely into the beginning portion of the right MCA. This would control circulation for the entire region of the right cerebral hemisphere by controlling blood flow into the completely ischemic right hemisphere (produced by interrupting the eight main arteries at the base of the brain on the right side) [21] (Fig. 8). In this model, however, brain ischemia was not avoidable during the procedures: cerebral blood flow decreased during the dissection and cannulation of the artery. Following carbon perfusion in this dog, carbon was found penetrating the right brain mantle alone, and perfusion for the entire region of the right cerebral hemisphere had not been achieved (Fig. 9).

The present model was developed as a model of brain perfusion that would be entirely physiological in nature. During all the procedures for preparing the model, brain ischemia in the left hemisphere (in which all the observations and sampling were made) was prevented by increasing the volume of infused blood at every clipping or

Fig. 6. Correlation between the volume of infused blood and $r \mathrm{CBF}$ in the territories of both anterior cerebral arteries. Note that the rCBF on the left side shoivs evidence of autoregulation while that on the right does not. (rCBF before operation: right, $29 \mathrm{ml} / 100 \mathrm{gm} / \mathrm{min} ;$ left, 28 $\mathrm{ml} / 100 \mathrm{gm} / \mathrm{min}$.)

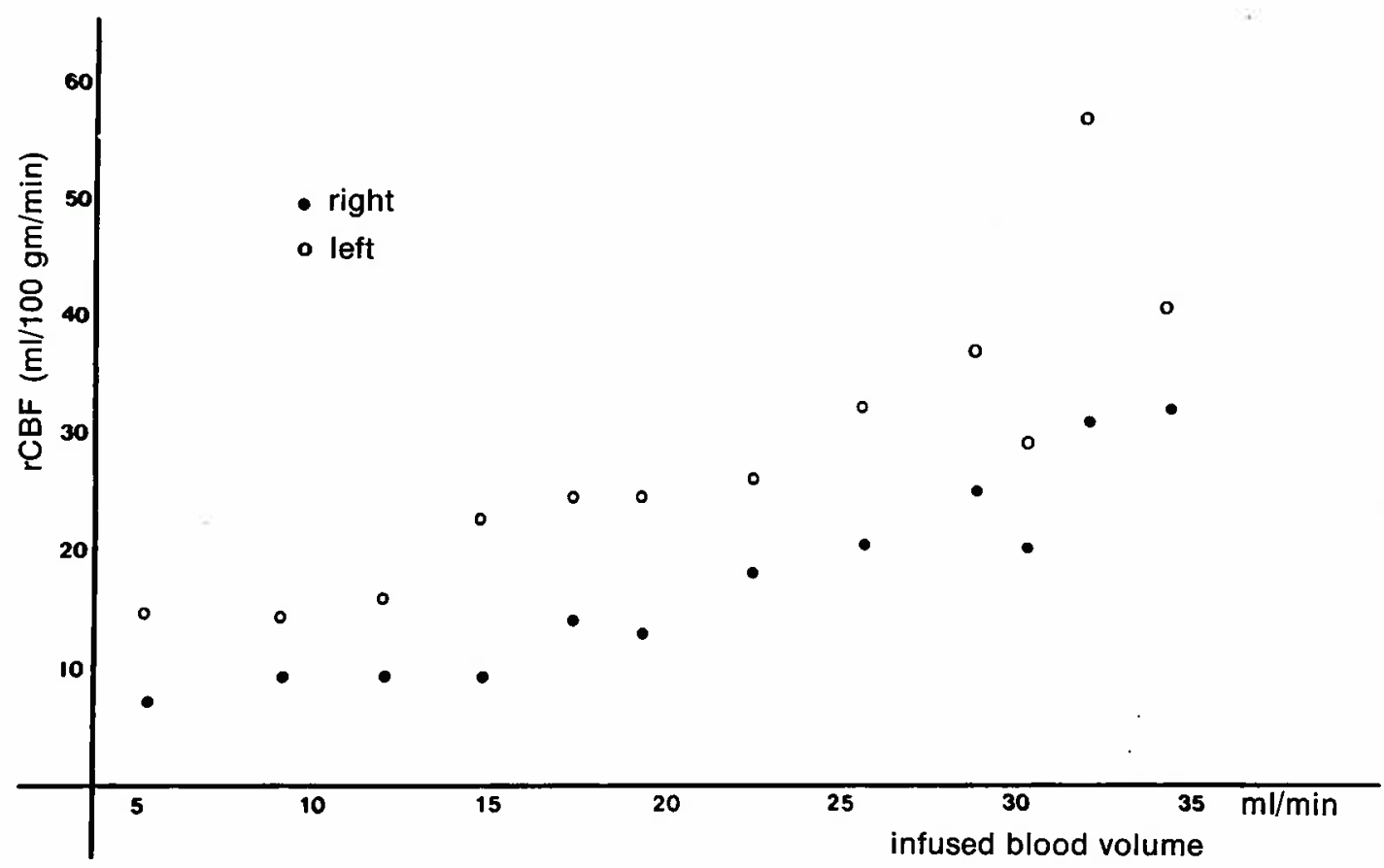




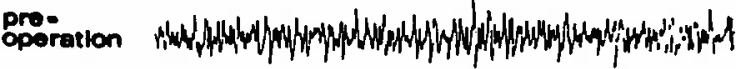

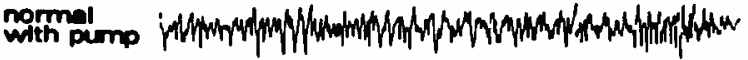

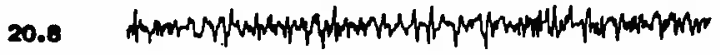

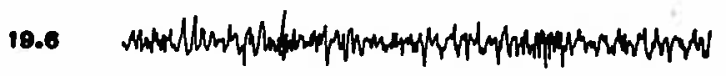

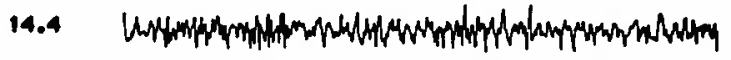

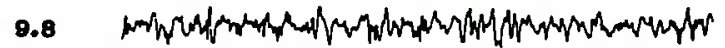

7.2

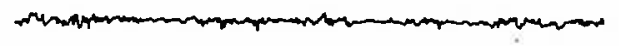

$\mathbf{0}$

$\mathrm{ml} / \mathrm{min}$

Fig. 7. Correlation between volume of infused blood and the cortical EEG in the left hemisphere. Between $20.8 \mathrm{ml} / 100 \mathrm{gm} / \mathrm{min}$ and 14.4 $\mathrm{ml} / 100 \mathrm{gm} / \mathrm{min}$ of infused blood, there is no difference in the cortical EEG; below $9.8 \mathrm{ml} / 100 \mathrm{gm} / \mathrm{min}$, low voltage and a slow wave appear in the cortical EEG. At $0 \mathrm{ml} / 100 \mathrm{gm} / \mathrm{min}$ the cortical EEG becomes completely flat.

occlusion of an artery. Cannulation of the right MCA was done retrogradely, making it possible to perfuse the entire left hemisphere through the circle of Willis. Although the right hemisphere (except the area fed by the right ACA) in this model was sacrificed and therefore was not suitable for experimental purposes, autoregulation in the left cerebral hemisphere continued to function normally (i.e., when the volume of blood being infused was increased in the left hemisphere, the rCBF retained a certain stability), as demonstrated in Figure 6. Due to the linear correlation between volume of infused blood and perfusion pressure, changes in blood flow to the left hemisphere show stability within a certain range proportionate to the perfusion pressure. The blood flow of the area fed by the right ACA shows a direct correlation with the volume of infused blood, indicating no autoregulation. From these findings, it is thought that the blood volume, which increases within the range of volume of infused blood at which the left hemisphere shows autoregulation, flows to the area that is fed by the right ACA. When compared with previous brain-perfusion models, the left hemisphere in our model is maintained under nearly physiological conditions.

Previous experimental models have had a low success rate in producing ischemic foci, and the site and size of the areas of ischemia have been inconstant. Furthermore, con-

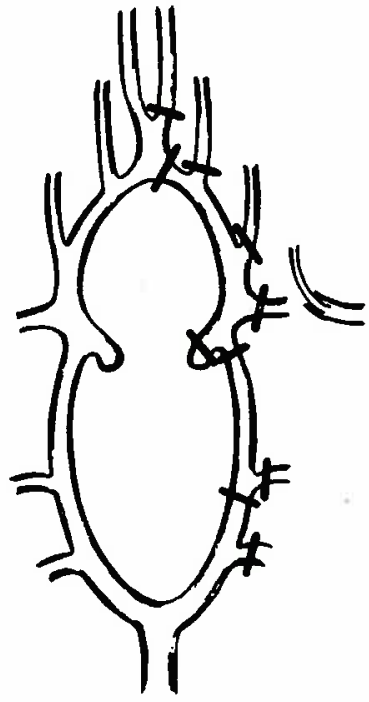

Fig. 8. The arteries of the brain, showing the occluded points and the cannula inserted anterogradely into the right MCA, in our initial model.

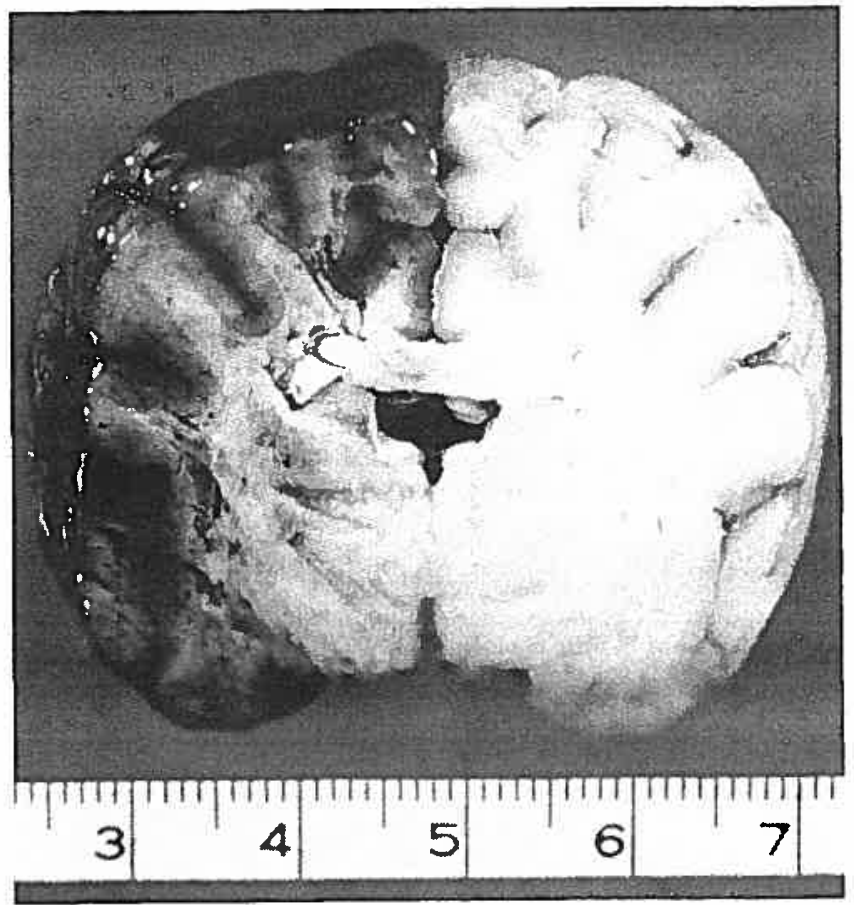

Fig. 9. Coronal view of the brain perfused with carbon black through the tube inserted anterogradely into the right MCA. The right hemisphere is perfused diffusely but only in the cerebral mantle. (Scale is in centimeters.) 
trol of the degree of ischemia has been impossible. In the present model it is possible to produce a focus of incomplete ischemia by reducing the volume of blood being infused to below $14 \mathrm{ml} / \mathrm{min}$. Complete ischemia can also be achieved in all animals immediately after reduction of the volume of blood being infused to $0 \mathrm{ml} / \mathrm{min}$. Hyperemia can be produced by increasing the volume to more than $23 \mathrm{ml} / \mathrm{min}$. In this model, since various degrees of hyperemia and ischemia can also be produced and recirculation of blood undertaken immediately by controlling the power of the infusion pump, it is also possible to study the very early stage of the condition by changing the blood flow. Additionally, it is possible to perfuse the brain through the cannulation tube with various drugs at differing concentrations, allowing for precise determination of the response of ischemic or normal brain tissue to known quantities of drugs. Since unilateral cerebral ischemia of varying severity can be produced, it is possible to obtain an abundance of tissue samples over an extended period from a single dog. This eliminates the problem of individual differences among dogs and makes feasible biochemical, morphological, and other studies of brain tissue. Since use of the pump to the brain is unavoidable, this model may not be useful for long-term experiments.

\section{References}

1. Bartko D, Reulen HJ, Koch H: Effect of dexamethasone on the early edema following occlusion of the middle cerebral artery in cats, in Reulen HG, Schumann K (eds): Steroids and Brain Edema. Berlin, Heidelberg, New York: Springer, 1972, pp 127-137

2. Brunson B, Robertson JT, Morgan H: The measurement of cerebral infarction edema with sodium 22 . Stroke $4: 461-464,1973$

3. Garcia JH, Kamijyo Y: Cerebral infarction: evolution of histopathological changes after occlusion of a middle cerebral artery in primates. J Neuropathol Exp Neurol 33:408-421, 1974

4. Geiger A, Magnes ]: The isolation of the cerebral circulation and the perfusion of the brain in the living cat. Am J Physiol 149:517-537, 1947

5. Gilboe DD, Drewes LR, Kintner D: Edema formation in the isolated canine brain. Anoxia vs ischernia, in Pappius HM, Feindel W (eds): Dynamics of Brain Edema. Berlin, Heidelberg, New York: Springer, 1976, pp 228-235
6. Gunn CG, Williams GR, Parker IT: Edema of the brain followin circulatory arrest. J Surg Res 2:141-143, 1962

7. Harrison MJG, Brownbill D, Lewis PD: Cerebral edema followin carotid artery ligation in the gerbil. Arch Neurol 28:389-391, 197:

8. Heymans C, Bouckaert Jj, Jourdar F, Nowak SJG, Farber S: Surviv: and revival of nerve centers following anemia. Arch Neurc Psychiatry 38:304-307, 1937

9. Hinzen DH, Muller U, Sotka P, Gerbert E, Lantz R, Hirsch H Metabolism and function of dog's brain recovering from longtim ischernia. Am J Physiol 223:2258-2264, 1972

10. Hossman KA: Development and resolution of ischemic brain swel ing, in Pappius HM, Feindel W (eds): Dynamics of Brain Edemt Berlin, Heidelberg, New York: Springer, 1976, pp 219-227

11. Ito U, Spatz $M$, Walter GT: Experimental cerebral ischemia in Mon golian gerbils. 1. Light microscopical observations. Acta Neuropatho (Berl) 32:209-223, 1975

12. Kahn K: The natural course of experimental cerebral infarction in th gerbil. Neurology 22:510-516, 1972

13. Kogure $K$, Busto $R$, Scheinberg $P$ : Energy metabolites and water cor tent in rat brain during the early stage of development of cerebré infarction. Brain 97:103-114, 1974

14. Little JR: Microvascular alterations and edema in focal cerebral iscl emia, in Pappius HM, Feindel W (eds): Dynamics of Brain Edem Berlin, Heidelberg, New York: Springer, 1976, pp 236-243

15. Meyer JS, Fukuuchi Y, Kanda T: Regional cerebral blood flow mea sured by intracarotid injection of hydrogen. Comparison of regiona vasomotor capacitance from cerebral infarction versus compression Neurology 22:571-584, 1972

16. Molinari GF: Experimental cerebral infarction. 1. Selective segmen tal occlusion of intracranial arteries in the dog. Stroke 1:224-231 1970

17. Olsson Y, Crowell RM, Klatzo I: The blood-brain barrier to proteir tracers in focal cerebral ischemia and infarction caused by occlusion o the middle cerebral artery. Acta Neuropathol (Berl) 18:89-102, 1971

18. Shibata S, Hodge CP, Pappius HM: Effect of experimental ischemi: on cerebral water and electrolytes. J Neurosurg 41:146-159, 1974

19. Siegel BA, Meidinger R, Elliot AJ: Experimental cerebral microem bolism. Multiple tracer assessment of brain edema. Arch Neuro 26:73-77, 1972

20. Siesjo BK: Circulation and oxygen consumption in the brain in Siesj. BK (ed): Brain Energy Metabolism. New York: Wiley, 1978, pp 96100

21. Suzuki J, Tanaka S, Yoshimoto T: Recirculation in the acute period o cerebral infarction: brain swelling and its suppression using mannitol Surg Neurol 14:467-472, 1980

22. Suzuki J, Yoshimoto T, Tanaka S, Sakamoto T: Production of variou models of cerebral infarction in the dog by means of occlusion of in tracranial trunk arteries. Stroke 11:337-341, 1980

23. Yoshimoto T, Sakamoto T, Suzuki J: Experimental cerebral infarc tion. Part 1: Production of thalamus infarction in dogs. Strok 9:211-214, 1978 